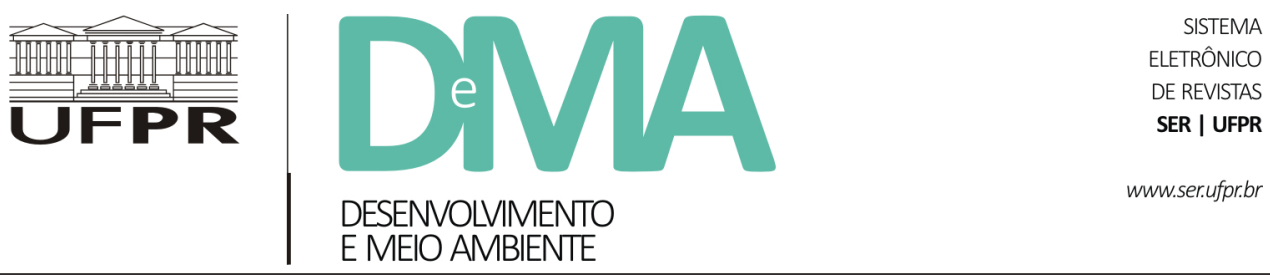

\title{
Desafios à gestão participativa na perspectiva dos gestores e conselheiros da Reserva Biológica Marinha do Arvoredo, Santa Catarina
}

\section{Challenges to Participatory Management from the Perspective of Managers and Counselors of the Arvoredo Marine Biological Reserve, Santa Catarina}

\author{
Dan Jacobs PRETTO ${ }^{1 *}$, Maria Paula Casagrande MARIMON ${ }^{2}$ \\ ${ }^{1}$ Instituto Chico Mendes de Conservação da Biodiversidade (ICMBio), Florianópolis, SC, Brasil. \\ ${ }^{2}$ Universidade do Estado de Santa Catarina (UDESC), Florianópolis, SC, Brasil. \\ *E-mail de contato: djpretto@hotmail.com
}

Artigo recebido em 13 de julho de 2017, versão final aceita em 18 de outubro de 2017.

RESUMO: Unidades de conservação (UCs) são áreas legalmente protegidas com limites definidos cuja função é a conservação da biodiversidade. Configuram-se como um instrumento de política pública na área ambiental e uma estratégia governamental de ordenamento territorial. A participação social na implementação das UCs é garantida por lei e organizada em arranjos institucionais específicos, denominados conselhos gestores. Entretanto, ainda são muitos os desafios para se alcançar a plena gestão participativa desses espaços protegidos. O objetivo do estudo que dá suporte a este artigo foi analisar a participação social desenvolvida no processo de criação e funcionamento do conselho consultivo da Reserva Biológica (REBIO) Marinha do Arvoredo, Santa Catarina. Para tanto, foram utilizadas metodologias de análise qualitativa. A coleta de dados envolveu a pesquisa bibliográfica e documental e a aplicação de entrevistas semiestruturadas com interlocutores selecionados (conselheiros e gestores). As informações documentais, sobretudo as atas das reuniões, revelaram aspectos importantes sobre o funcionamento do conselho, incluindo os assuntos tratados e a dinâmica do fórum. As entrevistas permitiram analisar o funcionamento do conselho na visão dos participantes, apontando os aspectos sobre os quais há mais ou menos convergência. A análise integrada dos dados coletados teve foco nos principais desafios ao pleno funcionamento do conselho, identificados e agrupados nos seguintes temas: falta de representatividade, baixa efetividade e falta de um entendimento claro sobre o papel do conselho. A partir desses apontamentos, são apresentadas algumas sugestões para o aperfeiçoamento desse processo participativo, entretanto, é fundamental que os integrantes do conselho assumam o papel central no debate sobre o foco 
dessa participação.

Palavras-chave: participação social; unidade de conservação; conselho.

ABSTRACT Protected areas (PAs) are locations legally protected whose main function is the conservation of biodiversity. They are an environmental policy instrument and a governmental strategy of territorial planning. Social participation in the implementation of PAs is guaranteed by law and organized into specific institutional arrangements, called councils. However, there are still many challenges to achieve a full participative management of these protected areas. The objective of the study that supports this article was to analyze the social participation developed in the process of the creation and functioning of the advisory council of the Arvoredo Marine Biological Reserve (REBIO), Santa Catarina. In order to achieve the objectives of this study, qualitative analysis methodologies were used. Data collection involved bibliographical and documental research and semi-structured interviews with selected interlocutors (counselors and managers). The documental information, especially the minutes of the meetings, revealed important aspects of the functioning of the council, including the issues and the dynamics of the forum. The interviews allowed to analyze the functioning of the council from the view of the participants, pointing out the aspects about which there is more or less convergence. The integrated analysis of the data collected focused on the main challenges to have the full functioning of the council, identified and grouped in the following themes: lack of representativeness, low effectiveness and lack of clear understanding of the role of the council. From these notes, some suggestions for the improvement of this participatory process are presented, however, it is fundamental that the members of the council assume the central role in the debate about the focus of this participation.

Keywords: social participation; protected area; council.

\section{Introdução}

O conceito de participação social e o debate sobre seus rebatimentos em políticas públicas não são recentes nem isentos de controvérsias (Irving, 2014). Também não escapam a inúmeros oportunismos de cunho ideológico e/ou político-partidário, para a qual inúmeras ambivalências e diferentes perspectivas teóricas e empíricas vem orientando o uso (ou o mau uso) dessa terminologia, e sobre a qual se tem uma falsa ideia de consenso na gestão pública (Dagnino, 2004).

Desde a democratização, houve um crescimento constante do que se refere à participação política no Brasil. Com a promulgação da Constituição de 1988 foi dada a partida para a formação de uma vasta institucionalidade participativa, que inclui conselhos, orçamentos participativos e pla- nos diretores municipais, entre outras formas de participação (Avritzer, 2011). Dentre os modelos propostos, a formação de conselhos gestores foi largamente instituída no país a partir desse período, consagrando-se como o espaço de participação mais difundido (Tatagiba, 2002). No entanto, a expansão quantitativa dos conselhos não significa necessariamente seu sucesso em superar os desafios a eles interpostos. De acordo com Gohn (2007), os conselhos gestores poderão ser tanto instrumentos valiosos para a constituição de uma gestão democrática e participativa, caracterizada por novos padrões de interação entre governo e sociedade em torno de políticas setoriais, como poderão ser também estruturas burocráticas formais e/ou simples elos de transmissão de políticas elaboradas por cúpulas, meras estruturas para transferência de parcos recursos para a comunidade, tendo o ônus de administrá-los; 
ou ainda, instrumentos de acomodação dos conflitos e de integração dos indivíduos em esquemas definidos previamente.

No campo das políticas ambientais, esse processo de participação social também encontra disposição legal, cabendo destacar os seguintes instrumentos: a Constituição Federal (art. 225); a Política Nacional de Meio Ambiente (PNMA) - Lei n. ${ }^{\circ}$ 6.938/1981; o Sistema Nacional de Unidades de Conservação (SNUC) - Lei n. ${ }^{\circ}$ 9.985/2000; e o Plano Estratégico Nacional de Áreas Protegidas (PNAP) - Decreto n. ${ }^{\circ}$ 5.758/2006. Segundo Irving (2014), a partir desse arcabouço legal, a democratização da gestão do patrimônio natural e o protagonismo social nas ações governamentais de proteção da natureza tornaram-se, então, um compromisso central em políticas públicas, ainda que, no primeiro momento, apenas no plano do discurso político.

Especificamente no âmbito da gestão de unidades de conservação (UCs), coube à lei do SNUC introduzir a obrigatoriedade e as diretrizes gerais sobre o tema, assegurando a participação efetiva das populações locais e demais atores na criação, implantação e gestão dessas áreas protegidas. Essa prerrogativa tem sido conduzida em três processos participativos distintos e de certa forma complementares: na criação de unidades de conservação (através de consultas públicas), na elaboração ou revisão do plano de manejo da UC, e na criação e no funcionamento do seu conselho gestor, foco deste artigo.

O conselho de unidade de conservação é uma instância colegiada formalmente instituída, cuja função é constituir-se em um fórum democrático de diálogo, valorização, participação e controle social, debate e gestão da UC, incluída a sua zona de amortecimento e território de influência, para tratar de questões ambientais, sociais, econômicas e culturais que tenham relação com a UC (Instrução Normativa ICMBio ${ }^{1} n^{\circ}$ 09/2014, art. $2^{\circ}$, inciso I). Este fórum é constituído formalmente e vinculado à estrutura de gestão da unidade de conservação, podendo ter caráter deliberativo ou consultivo, conforme a categoria da $\mathrm{UC}^{2}$.

Entretanto, apesar dos conselhos gestores existirem no cenário internacional há muito tempo e sob diferentes contextos (Gohn, 2007), esses espaços participativos são ainda muito recentes na história de implementação das unidades de conservação no Brasil, assim como na estrutura político-administrativa do seu órgão gestor. A existência legal destes espaços foi instituída somente a partir de 2000, pelo SNUC, ou seja, foram seis décadas de gestão de áreas protegidas sem uma agenda institucional voltada especificamente para esse tema (Figura 1). Com isso, o cenário pós-SNUC que se formou revelou um súbito crescimento no número de conselhos criados, num curto período de tempo, porém, carente de mecanismos normativos e de monitoramento das qualidades desses espaços participativos, aliado à ausência de capacitação dos técnicos responsáveis e dos atores envolvidos no processo. Logo, com base em alguns estudos de caso, verificou-se que as práticas adotadas no funcionamento desses conselhos tinham, em sua maioria, um caráter personificado, descontínuo e dissonante, entre outros problemas

\footnotetext{
${ }^{1}$ Instituto Chico Mendes de Conservação da Biodiversidade - ICMBio, autarquia federal vinculada ao Ministério do Meio Ambiente, responsável pela gestão das unidades de conservação federais.

${ }^{2}$ A lei do SNUC prevê a existência de dois tipos de conselhos: os deliberativos (especificamente para as categorias de manejo Reserva Extrativista - RESEX e Reserva de Desenvolvimento Sustentável - RDS) e os consultivos (para todas as demais categorias de manejo).
} 
(MMA, 2004).

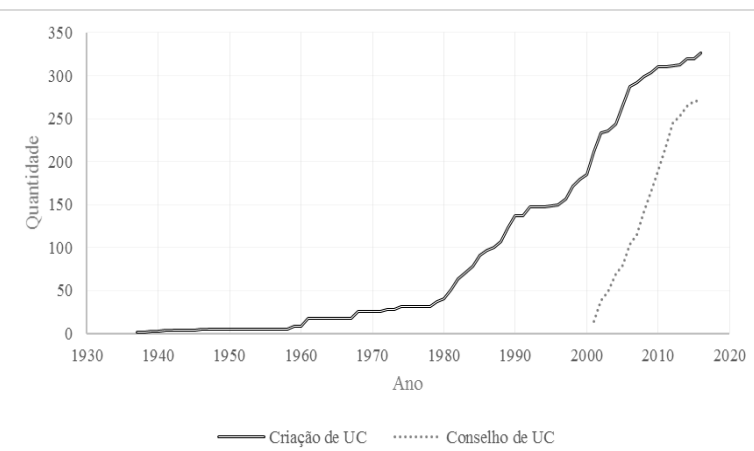

FIGURA 1 - Unidades de Conservação federais e conselhos gestores criados no Brasil de 1937 a 2016.

FONTE: ICMBio.

Para melhor compreender os aspectos qualitativos destes processos participativos, estudos têm apontado alguns fatores que são relevantes de serem observados, como: legitimidade, representação, representatividade, interação entre os conselheiros, compromisso governamental, comunicação, processos de aprendizagem, interesses, processo de criação do conselho, dinâmica, regras, normas existentes no funcionamento do conselho, entre outros (Tatagiba, 2002; MMA, 2004; Lüchmann, 2006; Gohn, 2007; Loureiro \& Cunha, 2008; Mendonça \& Talbot, 2014).

Portanto, o objetivo deste artigo foi analisar o processo de criação e funcionamento do conselho consultivo da Reserva Biológica (REBIO) Marinha do Arvoredo, com ênfase nos desafios e oportunidades desse processo participativo.

Analisar como foi instituído e como tem funcionado o conselho consultivo da REBIO Arvoredo é um passo importante para compreender a perspectiva conceitual que tem orientado a participação social na gestão desta unidade de conservação. A partir dessa leitura é possível refletir acerca dos desafios e das possibilidades deste fórum e dos meios para potencializar a consolidação de seus objetivos.

\subsection{Breve contextualização do processo de criação da REBIO Marinha do Arvoredo e dos conflitos ambientais associados}

A REBIO Arvoredo não possui em seu interior propriedades privadas, portanto, os conflitos ambientais instaurados a partir de sua criação estão relacionados ao uso do território (externo e interno) por diferentes atores, tendo em vista que o estabelecimento e a implementação da UC alteraram a dinâmica regional ao restringir o uso direto dos recursos naturais no seu interior e estabelecer novas regras de acesso aos recursos naturais na sua área de influência (externa). A identificação e caracterização desses conflitos foram descritas no processo de elaboração do plano de manejo da UC (IBAMA, 2004) e mais detalhadamente por Vivacqua (2005). Por ser uma unidade marinha localizada muito próxima à costa (aproximadamente $5 \mathrm{~km}$ a leste do ponto menos distante), os principais setores em conflito com a UC são: as comunidades de pescadores estabelecidas no seu entorno imediato (municípios de Florianópolis, Governador Celso Ramos, Tijucas, Bombinhas e Porto Belo), uma vez que esse território se constitui em área de pesca desses atores; e o turismo, especialmente àquele voltado à prática do mergulho recreativo, tendo em vista que as ilhas que compõem a UC são atrativos naturais para este tipo de atividade.

Importante destacar que a criação de uma unidade de conservação abrangendo o espaço físico onde atualmente se encontra a REBIO Arvoredo foi demandada por um movimento de atores locais, notadamente, no interesse de alguns grupos especí- 
ficos (i.e., movimento ambiental, setor do turismo e setor acadêmico). A REBIO Arvoredo foi criada em 1990 por meio de um decreto presidencial, porém, a categoria de manejo estabelecida frustrou os atores demandantes. Com o estabelecimento de uma Reserva Biológica ao invés de um Parque Nacional (categoria pretendida), inviabilizou-se qualquer atividade comercial no interior da UC. A atividade de pesca, todavia, é proibida nas duas categorias. Neste sentido, a determinação sobre a categoria de manejo criada (i.e. Reserva Biológica) foi decisão exclusiva do poder público, atendendo aos motivos expostos pelo IBAMA, que ressaltou a relevância biológica do local para justificar a necessidade de sua proteção integral. Todavia, não houve estudo técnico abrangente na região ou qualquer consulta pública sobre o processo de criação da unidade. Portanto, desde a sua concepção, existe um passivo social no que tange ao processo de criação desta unidade de conservação e o conselho consultivo foi sempre visto por muitos autores com certa expectativa de que esses conflitos pudessem ser mediados através deste espaço participativo (Costa, 2003; Vivacqua, 2005; Medeiros, 2009; Martins, 2012).

\subsection{Processos de formação e de reestruturação do conselho consultivo da REBIO Marinha do Arvoredo}

O conselho consultivo da REBIO Arvoredo (CORBIO) foi formado concomitantemente ao processo de elaboração do plano de manejo da unidade de conservação, ambos finalizados em 2004. Durante o processo, houve pelo menos três eventos relacionados à promoção da participação social e que, portanto, subsidiaram a equipe gestora na con- sequente formação do conselho consultivo. As instituições que integraram a formação inicial do CORBIO participaram das oficinas de elaboração do plano de manejo ou foram indicadas pelas instituições participantes no decorrer destes eventos.

Em outubro de 2012, durante a $13^{\text {a }}$ reunião ordinária, o CORBIO iniciou uma discussão sobre a necessidade de sua reestruturação, tendo como principais motivos: as faltas injustificadas de algumas instituições nas reuniões ordinárias, a busca pela paridade entre instituições públicas e da sociedade civil (na época, representavam aproximadamente $60 \%$ e $40 \%$, respectivamente), a saída de uma instituição da sociedade civil e a necessidade de ajuste no número de vagas para setores que ainda não integravam o conselho. O processo de reestruturação foi inicialmente conduzido por um grupo de trabalho (GT) e as decisões deliberadas posteriormente pela plenária do conselho. A nova portaria do CORBIO foi publicada em março de 2015 (Portaria ICMBio-CR9 nº1/2015), onde constam os atuais integrantes do conselho (Tabela 1).

Durante esse processo de reestruturação, mais precisamente na $18^{\mathrm{a}}$ reunião ordinária do CORBIO (março/2014), a Associação de Escolas e Operadoras de Mergulho de Santa Catarina (AEOMESC) entregou uma carta informando o seu desligamento do conselho, do qual vinha participando desde a sua criação. A saída da AEOMESC é um fato importante neste contexto visto que a instituição representa um dos setores diretamente afetados pela criação da REBIO Arvoredo. Entre os motivos do desligamento descritos na referida carta, destacam-se: a ausência de diálogo no conselho sobre assuntos de interesse do setor (i.e., mergulho recreativo) e a falta de implementação do plano de manejo da UC, documento do qual ajudaram a elaborar. 
TABELA 1 - Instituições integrantes do conselho consultivo da REBIO Marinha do Arvoredo (CORBIO), conforme Portaria CR9/ICMBio $\mathrm{n}^{\circ} 01 / 2015$.

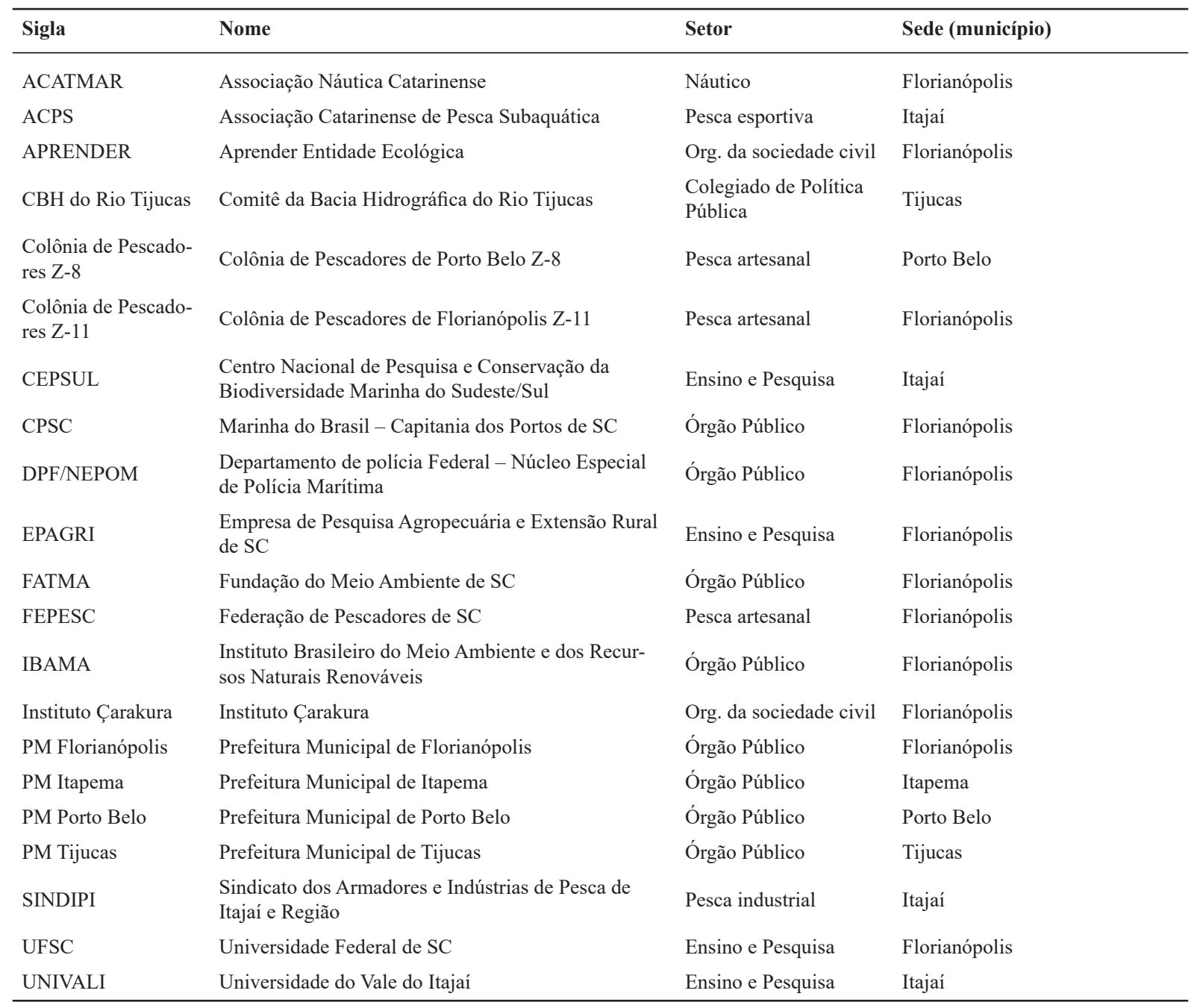

\section{Metodologia}

O trabalho foi desenvolvido tendo como referência o território de influência da Reserva Bio- lógica Marinha do Arvoredo (REBIO Arvoredo), unidade de conservação federal localizada no litoral central de Santa Catarina (Figura 2). Seu principal objetivo de criação é a proteção de amostra representativa dos ecossistemas da região, suas ilhas e 
ilhotas, águas e plataforma continental com todos os recursos naturais associados.

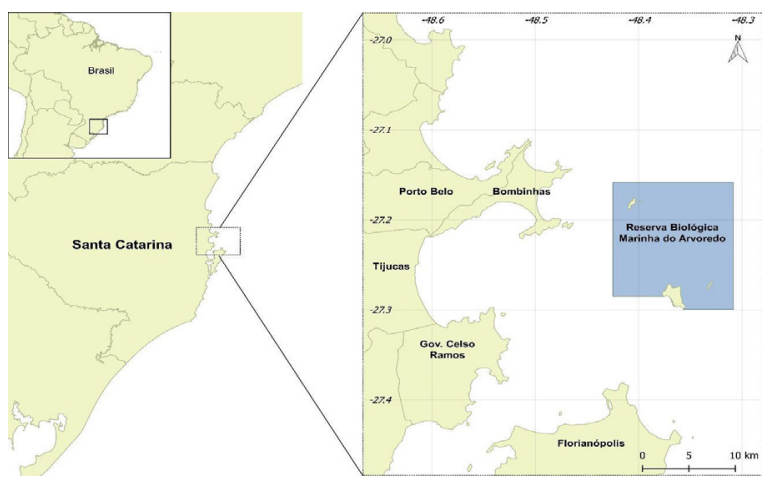

FIGURA 2 - Localização da Reserva Biológica Marinha do Arvoredo, Santa Catarina.

FONTE: IBGE e ICMBio.

A unidade é composta de quatro ilhas (representando 3\% de sua área superficial) e o ambiente marinho associado (representando 97\% de sua área superficial), totalizando $17.600 \mathrm{ha}$.

A pesquisa que dá suporte a esse artigo tem caráter exploratório e descritivo (Marconi \& Lakatos, 2003) e foi esquematizada sob a forma de um estudo de caso (Gil, 1999). As técnicas de coleta de dados utilizadas incluíram a análise documental e a entrevista. $\mathrm{Na}$ análise documental foram compiladas informações contidas em três processos administrativos do ICMBio, os quais tratam da criação, da implementação e da reestruturação do conselho consultivo da REBIO Arvoredo. Dentre as peças destes processos administrativos, as atas das reuniões certamente são aquelas que contêm o maior volume de informações sobre o funcionamento do conselho.
As entrevistas foram realizadas com foco em dois perfis de informantes: (i) os atuais conselheiros ${ }^{3}$ da REBIO Arvoredo (o presidente do conselho, que é o chefe da UC, foi entrevistado na condição de gestor), com o mandato (2015-2017) instituído pela Portaria CR9-ICMBio $n^{\circ} 01 / 2015$; e (ii) os quatro gestores ou presidentes do CORBIO (o atual e três ex-chefes da REBIO Arvoredo).

Todas as entrevistas foram individuais, permitindo assim uma interação mais direta entre pesquisador e entrevistado. Por outro lado, Boni \& Quaresma (2005) advertem que a ausência de outros interlocutores no debate possibilita a perda do diálogo coletivo, da troca de experiências e da formulação de ideias a partir de outros pontos de vista. Tendo isto em vista, foi realizada uma apresentação dos principais resultados obtidos pelas entrevistas individuais à plenária do $\mathrm{CORBIO}$ durante sua $31^{\circ}$ reunião ordinária (em 08/06/2017). Esta apresentação, seguida de um debate, teve o intuito de ser uma devolutiva e uma forma de integração acerca dos dados obtidos com o trabalho desenvolvido.

Para a realização das entrevistas foram aplicados questionários semiestruturados (Boni \& Quaresma, 2005), contendo questões relativas ao (i) perfil do entrevistado, ao (ii) perfil da unidade de conservação e ao (iii) perfil do conselho consultivo da REBIO Arvoredo.

\section{Resultados e discussão}

Os resultados suscitados pela análise documental e pelas entrevistas apontaram as qualidades

\footnotetext{
${ }^{3} \mathrm{O}$ conselho consultivo da REBIO Arvoredo é composto atualmente por 22 instituições (Portaria CR9-ICMBio nº1/15), entretanto, duas instituições (Prefeitura Municipal de Tijucas e Colônia de Pescadores Z-11) não tinham representantes indicados durante o período de realização do estudo, portanto, foram entrevistados somente 19 conselheiros, além do presidente.
} 
do conselho consultivo da REBIO Arvoredo. A análise do conselho, na visão dos seus integrantes (conselheiros e gestores), permitiu verificar as questões de maior convergência (expectativas quanto à participação no conselho; objetivos do conselho; resultados alcançados pelo conselho) e divergência (possibilidade de o conselho assumir atribuições de gestão da UC; existência de momentos deliberativos nas reuniões do conselho; influência do órgão gestor no funcionamento do conselho) entre os participantes.

Os principais desafios ao pleno funcionamento desse processo participativo foram identificados e agrupados em três temas, que serão discutidos a seguir: a falta de representatividade, a baixa efetividade na implementação de ações e a falta de um entendimento claro sobre o papel do conselho. $\mathrm{O}$ desdobramento desses temas nos leva a incluir uma discussão acerca do papel do conselho na integração da unidade de conservação com o seu entorno.

Como ponto de partida, porém, cabe fazer um destaque para os resultados apontados pela análise documental. Estes dados revelaram as características de funcionamento do conselho consultivo da REBIO Arvoredo, com destaque para os seguintes aspectos:

- A agenda (pauta) do CORBIO pouco tratou de assuntos conflituosos nestes treze anos de fun- cionamento. $\mathrm{O}$ foco dado à participação social no conselho da REBIO Arvoredo tem sido bastante restrito ao tratamento de assuntos funcionais $\mathrm{e}$ burocráticos do conselho e da unidade de conservação. Além disso, as reuniões possuem um caráter bastante informativo e técnico. Pouca atenção tem sido dada aos problemas territoriais envoltos à REBIO Arvoredo. Ou seja, não houve, de fato, uma abertura de diálogo sobre assuntos de interesse dos setores mais afetados pela criação da UC (i.e., pesca e mergulho), frustrando neste aspecto, as expectativas sobre o processo participativo;

-Nesses 13 anos de funcionamento, o CORBIO se manifestou politicamente apenas em dois momentos, através de duas moções. A primeira moção (de 31/05/2012) foi elaborada com o intuito de manifestar o posicionamento do CORBIO acerca do processo de recategorização $0^{4}$ da unidade de conservação. A segunda moção (de 19/11/2015) foi dirigida especificamente ao Presidente do ICMBio e ao Procurador Chefe da Procuradoria da República em Santa Catarina (PRSC/Ministério Público Federal), solicitando o reestabelecimento da Zona de Amortecimento ${ }^{5}$ da REBIO Arvoredo ${ }^{6}$. Ou seja, o conselho pouco atuou politicamente acerca de assuntos territoriais ligados à unidade de conservação, embora esta seja uma de suas atribuições legais (Decreto $n^{\circ} 4.340 / 2002$ ).

\footnotetext{
${ }^{4}$ Projeto de Lei no 4.198/2012 propõe a alteração da categoria "Reserva Biológica" para "Parque Nacional" (categoria de manejo que permite a visitação pública), continua tramitando na Câmara dos Deputados. Atualmente o PL está na Comissão de Meio Ambiente e Desenvolvimento Sustentável (CMADS) aguardando parecer do Relator (consultado em 01/06/2017).

${ }^{5}$ Zona de Amortecimento (ZA): o entorno de uma unidade de conservação, onde as atividades humanas estão sujeitas a normas e restrições específicas, com o propósito de minimizar os impactos negativos sobre a unidade (SNUC, Lei $\mathrm{n}^{\circ}$ 9985/2000, art. 2º inciso XVIII).

${ }^{6}$ A Zona de Amortecimento da REBIO Arvoredo (i.e., seus limites e regramentos), foi construída durante o processo de elaboração do Plano de Manejo (PM) da UC, tornando-se imediatamente válida a partir da publicação deste documento (10/09/2004). Porém, em 01/09/2014, o PM foi republicado pelo ICMBio e a respectiva ZA foi considerada como uma proposta, a qual depende da publicação de um instrumento jurídico específico para ter validade, o que não foi realizado até o momento.
} 
Portanto, a ausência de integração da unidade de conservação com o seu entorno fica evidenciada nos registros documentais do conselho, sendo um problema comum em ambos os casos citados acima. Tendo em vista que as diretrizes institucionais existentes no arcabouço legal sobre unidades de conservação dão total respaldo para que o conselho atue neste sentido, é necessária uma alteração no foco dado à participação no CORBIO para englobar este objetivo na sua agenda.

\subsection{Representatividade}

Dentre os problemas que se apresentam, a representatividade foi uma das questões priorizadas tanto pelos conselheiros quanto pelos gestores. De acordo com os entrevistados, o problema está relacionado, principalmente, ao desligamento do setor de mergulho do conselho e a ausência de representantes da pesca artesanal nas reuniões do conselho. Entretanto, embora a pesca artesanal e o mergulho comercial estejam distantes do CORBIO, é importante destacar que a representação destes dois setores possui contextos absolutamente distintos. Enquanto que as operadoras de mergulho sempre estiveram na linha de frente dos debates sobre a unidade de conservação, com representações politicamente articuladas o setor da pesca artesanal constitui um grupo social que nunca exerceu a mesma força política, sobretudo no âmbito desta UC. Além do mais, a saída das operadoras de mer- gulho do conselho foi uma decisão deliberada pelo próprio setor, enquanto que a ausência do setor da pesca artesanal dos processos participativos é consequência, sobretudo, de um processo histórico de marginalização social aliada às suas frágeis formas de estruturação organizacional, ainda baseada nas colônias ${ }^{7}$ de pescadores (Vasconcellos et al., 2007).

Soma-se a estes fatos representativos, o insucesso do próprio ICMBio em promover efetivamente a participação dos pescadores no conselho. Embora nunca tenha sido colocado óbice à participação do setor nos processos participativos da UC, na opinião de Vivacqua \& Vieira (2005), os conflitos vivenciados pelos pescadores após a criação da REBIO Arvoredo traduziram-se em algumas ações individuais e fragmentadas no âmbito dos espaços participativos desta UC. Por outro lado, essas participações têm se mostrado importantes para promover oportunidades de colocar em cena atores sociais historicamente marginalizados dos processos decisórios, ainda que os ganhos sejam pontuais. Talvez o resultado mais concreto da participação de representantes dos pescadores nos processos participativos da REBIO Arvoredo tenha sido durante a elaboração do plano de manejo da UC, quando duas medidas reivindicadas pelo setor foram contempladas no documento: as Áreas de Restrição à Pesca de Arrasto (baías de Tijucas, Zimbros, Mariscal, Bombas e Bombinhas, Porto Belo e Itapema) e a Área de Normatização de Pesca e Turismo ${ }^{8}$, ambas inseridas na Zona de Amortecimento (ZA) da REBIO Arvoredo (IBAMA, 2004). Tendo em vista os

\footnotetext{
${ }^{7}$ Ainda que, de acordo com a Constituição (1988), a colônia não seja a única representação dos pescadores, ela continua sendo a principal, tendo sido criada nas primeiras décadas do século XX, pela Marinha do Brasil. No entanto, são poucas as colônias dirigidas por pescadores, sendo muitos os presidentes provenientes de outras categorias como vereadores, atravessadores, profissionais liberais, entre outros, que atrelam interesses dos pescadores ao clientelismo local. Na maioria das vezes as colônias são entidades meramente assistencialistas (Vasconcellos et al., 2007, p. 23). ${ }^{8}$ Área de Normatização de Pesca e Turismo: área integrante da Zona de Amortecimento da REBIO Arvoredo, com aproximadamente 91 mil hectares e circunscrita às imediações da unidade de conservação. Possui normas específicas visando o ordenamento das atividades de pesca e
} 
benefícios para o ordenamento pesqueiro na região, Martins et al. (2014) registraram que essas medidas são reconhecidas e consideradas importantes pelos pescadores da baía de Tijucas entrevistados em seu trabalho. Entretanto, a falta de fiscalização efetiva por parte dos órgãos públicos sempre gerou desconfiança entre esses pescadores acerca da efetividade dessas medidas (Medeiros, 2009; Martins et al., 2014). Para piorar, a ZA da REBIO Arvoredo não está em vigor desde 2014, o que certamente contribui ainda mais para o descrédito do órgão gestor frente a esses atores. Ou seja, como resultado do processo de negociação de um dos conflitos mais evidentes no contexto da REBIO Arvoredo, podemos presumir que, até o momento, "andamos um passo para frente e dois para trás", pois apesar das medidas reivindicadas pelos pescadores terem sido incorporadas ao plano de manejo da UC, as mesmas não foram implementadas conforme deveriam e a perda de credibilidade do órgão gestor frente aos pescadores certamente desgastou ainda mais essa relação, tornando o processo de reconciliação cada vez mais desafiador.

Portanto, sendo a representatividade um fator central da legitimidade do espaço participativo (Gohn, 2007; Abers \& Keck, 2008; Loureiro \& Cunha, 2008), o CORBIO não tem tido sucesso em atender plenamente a esse pressuposto, baseado no fato de que justamente os atores mais afetados pelo processo de criação da UC estão ausentes do processo participativo. Segundo Loureiro \& Cunha (2008), os conselhos têm o potencial para estimular a ampliação dos processos democráticos, mas para tanto, devem ser instâncias legitimadas pelos diferentes atores sociais, envolvendo, efetivamente, grupos que sempre estiveram à margem das decisões relativas à gestão dessas áreas protegidas e que são, de maneira geral, os mais afetados pela existência da unidade de conservação.

Nesta perspectiva, é essencial que haja uma integração entre os atores do entorno e a gestão da UC para se estabelecer um debate legítimo sobre os conflitos ligados à pesca na área de influência da UC (Vivacqua, 2005; Medeiros, 2009; Martins et al., 2014; Alves \& Hanazaki, 2015). De acordo com Abers \& Keck (2008), é dever do Estado buscar o equilíbrio entre a diversidade e a igualdade das representações no conselho, garantindo que os interesses de todos possam ser representados, sobretudo daqueles grupos excluídos e menos organizados.

Sem desconsiderar a contribuição dos demais integrantes do conselho, cabe, entretanto, à gestão da REBIO Arvoredo o dever de buscar novas formas de promover a participação do setor da pesca no âmbito do CORBIO e, se necessário, lançar mão de novas estratégias que permitam o estabelecimento de um diálogo efetivo, em complementação ao espaço disponibilizado pelo conselho (Mendonça $\&$ Talbot, 2014), a exemplo de reuniões setoriais, do desenvolvimento projetos de integração com o apoio de mediadores, entre outras ações.

\subsection{Efetividade}

Outro problema destacado pelos entrevistados diz respeito à baixa efetividade do conselho, sobretudo em relação a não implementação daquilo que

de turismo na região, com destaque para a proibição de pesca com embarcações maiores do que 10 AB (arqueação bruta), favorecendo desta forma, as embarcações de pequeno porte nesta área. 
é tratado nas reuniões. Entretanto, de acordo com os depoimentos, essa questão foi relacionada tanto à efetividade de atuação do conselho em si quanto à efetividade de implementação da unidade de conservação. Isso demonstra que existe uma influência da segunda questão (nível de implementação da UC) sobre a percepção (de fracasso ou sucesso) da primeira (efetividade do conselho). A confusão que se cria está relacionada justamente a um dos objetivos do conselho, que é o de apoiar a gestão da REBIO, de modo que muitos assuntos abordados nas reuniões dizem respeito às ações previstas para a implementação da UC. A partir do momento em que os assuntos tratados no conselho não se traduzem em ações concretas em prol da UC, cria-se um ambiente de frustração, inclusive, sobre a percepção da efetividade de atuação do próprio conselho.

Apesar de relacionados, o nível de implementação de uma UC não deve ser determinante na avaliação de efetividade de seu conselho, sobretudo como um espaço político (Dagnino, 2002; Loureiro \& Cunha, 2008). Pensar o problema da efetividade significa conseguir estabelecer algum tipo de comparabilidade sobre resultados produzidos por estes espaços participativos (Avritzer, 2011). Essa tarefa é ainda mais difícil já que a participação implica tanto um elemento valorativo quanto um elemento político. A participação pode ser considerada desejável como um valor em si ou em função dos seus efeitos, quer dizer, pela sua capacidade de ser útil para a produção de consequências julgadas valiosas. Se aquilo que é apreciado são as consequências, a participação é valorizada pela sua utilidade, ou seja, é um meio para a produção de efeitos. Se, de outro lado, a participação é desejável em si, é considerada valiosa à margem de considerações a respeito da sua utilidade, sejam quais forem suas consequências (Lavalle, 2011). Portanto, qualquer avaliação que se faça neste sentido, é fundamental que se considere tanto a atuação funcional (técnica) quanto a atuação (e formação) política do conselho.

Dessa forma, apesar das questões de funcionamento dos conselhos serem relevantes na análise dessas instâncias como arenas de conflitos ambientais, o enfoque político não pode ser negligenciado (Mendonça \& Talbot, 2014). Para a maioria dos entrevistados, o foco dado à efetividade da participação teve ênfase nas questões funcionais e técnicas do conselho, enquanto que poucos relacionaram esta questão ao seu papel político. Neste aspecto, há que se considerar inclusive a tendência de concentrar a atuação do conselho (pauta, debates, capacitação, etc.) em temas técnicos sobre a REBIO Arvoredo e seu entorno, em detrimento de assuntos envoltos à integração da unidade de conservação com o seu entorno. Segundo Acselrad (2004), ao concentrar o debate no aspecto técnico (e não político) da questão ambiental, o conselho reduz a própria expressão política dos atores sociais envolvidos no debate. Esse processo desqualifica a capacidade e competência de atores sociais, sobretudo daqueles em estado de vulnerabilidade, em discutir questões que os afetam (Acselrad, 2004).

\subsection{Papel do conselho}

A falta de clareza sobre o papel do conselho consultivo também foi citada como um problema ao pleno funcionamento do fórum. Trata-se, porém, de um tema transversal a todos os demais discutidos até aqui. A falta de um entendimento sobre esse papel, seja pelos gestores ou pelos conselheiros, restringe 
a sua atuação funcional e política ao atendimento de ações imediatistas e burocráticas (Lüchmann, 2002). Viabilizar e efetivar a participação popular no processo de gestão são tarefas distintas e exigem conhecimento e qualificação para o tratamento da relação entre aspectos técnicos e políticos da gestão participativa. Para Gohn (2007), o papel dos conselhos incide na discussão sobre as estratégias de gestão pública de uma forma geral e sobre o caráter das próprias políticas públicas em particular.

Dessa forma, a concepção de democracia subjacente aos processos de participação social implica alterações significativas de perspectivas teóricas e ideológicas da relação entre Estado e sociedade civil presentes no ideário político brasileiro (Silva, 2004).

Nesta perspectiva, a participação ampliada de atores sociais em processos de tomada de decisão tende a ser objeto de intensa disputa política (Santos \& Avritzer, 2005) e ideológica, o que não é diferente no âmbito das políticas ambientais praticadas no país. Distintas concepções quanto às relações entre sociedade e natureza e de conservação da biodiversidade disputam espaço na agenda ambiental. No âmbito do ICMBio, ainda que seja possível identificar um amadurecimento nas ações voltadas para a compreensão mútua das diversas correntes com relação à importância dos diferentes olhares sobre a conservação para uma gestão ambiental mais efetiva, os ganhos ainda são pontuais (Mendonça $\&$ Talbot, 2014).

Segundo Tatagiba (2002), a dinâmica interna desses fóruns é marcada por relações verticalizadas, com forte viés autoritário, uma vez que há resistências das estruturas governamentais em aceitar o padrão partilhado de gestão, fazendo-o parecer como um mecanismo que dificulta o processo decisório. Como bem salienta a autora, os encontros entre Estado e sociedade civil nos conselhos têm sido afetados negativamente por uma grande recusa do Estado em partilhar o poder de decisão. Os governos têm resistido (de forma mais ou menos acentuada, dependendo da natureza do governo e do seu projeto político) às novas formas de fiscalização, controle e participação da sociedade civil no processo de produção das políticas públicas (Tatagiba, 2002). Santos \& Avritzer (2005) também nos alertam sobre a descaracterização da participação, quer pela cooptação por grupos sociais incluídos, quer pela integração em contextos institucionais que lhe retiram o seu potencial democrático e de transformação das relações de poder. Para os autores, a burocratização da participação é uma das formas de sua perversão.

Pelas entrevistas realizadas, o excesso de burocracia do órgão gestor foi uma das características relacionadas ao funcionamento do CORBIO. Mendonça \& Talbot (2014) afirmam que a conjugação da frágil participação social na criação e implementação das unidades de conservação com a baixa capacidade ${ }^{9}$ do Estado brasileiro em administrar estes territórios protegidos, é hoje uma das principais raízes dos conflitos enfrentados na gestão. Todavia, algumas experiências participativas

\footnotetext{
${ }^{9}$ No que diz respeito à "capacidade" do Estado em implementar as políticas públicas ambientais, é importante considerar a argumentação de Silva (2004, p.198-199): "No entanto, cabe destacar que não se pode deixar de apreender as determinações (aparentemente crescentes) que a configuração do sistema capitalista contemporâneo impõe à ação estatal. A desconsideração por este aspecto parece se expressar, por exemplo, no relativo afastamento entre as análises que discutem, de um lado, o aprofundamento da democracia e a expansão da cidadania através dos processos de participação e, de outro, aquelas que abordam a crise de financiamento do Estado e as suas limitações em termos de implantação das políticas públicas. Como uma forma de recusa às perspectivas deterministas, tende-se, muitas vezes, a desconsiderar limitações estruturais impostas à ação estatal e reduzir tudo ao aspecto da "vontade política".
} 
no âmbito das unidades de conservação têm demonstrado que outras formas de gestão são possíveis. Essas iniciativas se apoiam na importância do reconhecimento dos contextos ambiental e sociopolítico do território de influência da unidade de conservação e na participação social com foco na integração da unidade com a dinâmica regional, utilizando-se de instrumentos de gestão apropriados. A seguir abordaremos alguns aspectos desta concepção.

\subsection{Integração com o entorno (mediação de conflitos)}

Historicamente, as unidades de conservação foram criadas e geridas como "ilhas" isoladas do contexto regional na qual estão inseridas, desconexas de outros interesses e políticas territoriais. A partir da previsão de uma gestão participativa para esses espaços protegidos, a leitura que se fazia sobre a integração da unidade de conservação com o seu entorno foi atribuída também aos conselhos, conforme previsto na legislação pertinente (i.e. Esforçar-se para compatibilizar os interesses dos diversos segmentos sociais relacionados com a unidade; Propor diretrizes e ações para compatibilizar, integrar e otimizar a relação com a população do entorno - Decreto Federal n4340/2002, art. 20, incisos IV e IX). No entanto, para que essa interação ocorra de fato e extrapole a discussão envolta somente dos problemas “internos” da UC, há que se iniciar um debate fora da atual "zona de conforto", considerando o papel do conselho na integração e articulação das políticas públicas no território (Delgado et al., 2007).

A partir dessa perspectiva, os conselhos de uni- dades de conservação têm o potencial de ser um fórum público importante para a articulação das políticas públicas no território, colaborando com a inserção da unidade na dinâmica regional (Mendonça \& Talbot, 2014). Para tanto, os diferentes interesses existentes no território devem fazer parte da agenda do conselho, sem que haja nenhuma forma de acomodação dos conflitos (Gohn, 2007). O conselho não é espaço para homogeneizar as diferentes matrizes de pensamento, mas sim um espaço de reconhecimento das contradições geradas pelo processo de conservação da natureza. Apoiar a gestão da unidade de conservação faz sentido nesta perspectiva, explicitando as diferentes percepções do território na busca por mecanismos que possam regulamentar os conflitos ambientais (Zhouri \& Laschefski, 2010) e consequentemente integrar a UC na dinâmica regional na qual está inserida.

No entanto, para que essa mudança de foco seja possível, torna-se necessário imbuir no próprio conselho consultivo, a responsabilidade de reconhecer e assumir o passivo social deixado pela criação desta unidade de conservação. Isso leva a considerar os resultados das entrevistas realizadas com os integrantes desse processo participativo, para entendermos a visão desses atores sobre o contexto territorial da REBIO Arvoredo.

As entrevistas revelaram que existe uma convergência na visão dos gestores e conselheiros quanto aos principais conflitos existentes no território de influência da REBIO Arvoredo, que são: os setores da pesca e do mergulho. De uma forma geral, há entre os participantes do conselho o reconhecimento dos passivos sociais deixados pela criação da UC.

A experiência adquirida pelo envolvimento do setor pesqueiro nos processos participativos da REBIO Arvoredo (sobretudo no plano de manejo) 
tem indicado que o caminho por onde os conflitos podem ser negociados de fato precisa de instrumentos de gestão adequados e de uma abordagem focada na gestão territorial integrada e participativa, em oposição ao modelo tradicional de gestão tecnocrática, centralizada e isolada da dinâmica regional. Essa abordagem faz sentido não só na perspectiva do envolvimento e integração dos diversos interesses e atores em jogo, mas também no contexto dos objetivos de conservação da própria unidade de conservação, a qual depende que outros ecossistemas marinho-costeiros relacionados sejam igualmente protegidos e manejados de forma adequada (Martins et al., 2014).

Dessa forma, os instrumentos de gestão são essenciais para que o processo de negociação possa se concretizar institucionalmente, ultrapassando assim os limites do diálogo (Silva, 2004).

A gestão territorial integrada e participativa é relevante tanto para a abordagem dos conflitos gerados pelo processo de criação da REBIO Arvoredo, ausente de qualquer consulta aos atores do entorno, assim como, para a abordagem da própria gestão pesqueira praticada historicamente no país, ausente de um ordenamento apropriado, participativo e inclusivo (Dias-Neto, 2010; Haimovici et al., 2014), particularmente trágico ao setor da pesca artesanal e de pequena escala (Rebouças et al., 2006; Vasconcellos et al., 2007).

Neste caso, pelo menos três estratégias de ação podem ser deslumbradas no contexto do conselho consultivo da REBIO Arvoredo:

1. Conduzir debates para a construção de uma gestão pesqueira compartilhada no território de influência da UC, nos limites de sua competência, utilizando-se dos próprios instrumentos disponíveis para a gestão da unidade de conservação (por exem- plo: plano de manejo, zona de amortecimento, termo de compromisso, entre outros) - prática já adotada anteriormente durante o processo de elaboração do plano de manejo da REBIO Arvoredo, com a inclusão de medidas de ordenamento pesqueiro no entorno da UC;

2. Atuar politicamente junto às instâncias responsáveis legalmente pela gestão pesqueira e outros órgãos interessados, incluindo-os no debate, solicitando e cobrando que sejam criados os fóruns locais de gestão da pesca, alguns deles já previstos em legislações específicas, mas que nunca saíram do papel (e.g. Instrução Normativa n ${ }^{\circ}$ 12/2012 MPA/MMA). Outras formas de negociação entre os diversos atores também são possíveis, a exemplo do que foi conduzido na definição dos limites para a pesca de arrasto na Baía Norte de Santa Catarina (Steenbock et al., 2015), mas que exigem, como ponto de partida, a representatividade, o diálogo e o compromisso entre as partes.

3. Inserção efetiva nos espaços políticos já constituídos, como o GERCO/SC e o Comitê de Bacias do Rio Tijucas, por exemplo (Andrade \& Scherer, 2014).

Abordagens dessa natureza são realidades no contexto de outras unidades de conservação marinhas, seja no âmbito dos seus respectivos conselhos ou não (Seixas \& Kalikoski, 2009; Adriano, 2011; Joventino et al., 2013).

Não se trata, contudo, de atribuir a gestão pesqueira e o seu passivo ao conselho consultivo da REBIO Arvoredo ou à gestão da $\mathrm{UC}$, mas sim de se apropriar de instrumentos já existentes no intuito de fortalecer os objetivos do conselho consultivo e da própria unidade de conservação, engajando a sociedade num processo efetivo de gestão participativa.

Por fim, mesmo que essa discussão tenha se 
apoiado nos aspectos do conflito com a pesca, não há restrições para que posturas políticas específicas e instrumentos de gestão similares possam ser adotados para a mediação de outros conflitos, como por exemplo, com o setor do mergulho e turismo náutico, debatendo-se participativamente propostas de ação, algumas já sugeridas em outros momentos (Strenzel, 1997).

\section{Conclusões}

O conselho da REBIO Arvoredo não constitui panaceia para os problemas enfrentados pela gestão da unidade de conservação, entretanto, é um espaço fundamental para o estabelecimento de uma nova relação entre o órgão gestor e os atores presentes no território de influência da UC, assim como, para a integração desta unidade na dinâmica regional na qual está inserida.

Apesar do conselho da REBIO Arvoredo ter sido instituído há treze anos, as características de seu funcionamento e, consequentemente, o foco dado à participação social neste espaço nunca tinham sido tema de análise, procedimento que se revelou essencial para entender os desafios e as potencialidades deste fórum, no intuito de buscar o seu aperfeiçoamento. Este artigo elencou as principais qualidades do conselho consultivo da REBIO Arvoredo e mostrou que ainda há muito que se considerar sobre alguns obstáculos ao seu pleno funcionamento, sobretudo quanto à sua representatividade, sua atuação política e o foco dado à participação social no cumprimento de seus objetivos. Obviamente, nenhum dos obstáculos identificados impede o seu funcionamento, entretanto, impõe limites à sua legitimidade, restringe o seu potencial de atuação e gera frustrações entre os integrantes (gestores e conselheiros). Se os espaços participativos não produzem mudanças significativas ou se eles não são percebidos como propiciadores de processos de mudança, então se torna menos provável que os participantes continuem a investir neles. Sugere-se, então, que as questões levantadas sejam apropriadas pelos integrantes do conselho e sirvam de base para um debate mais profundo e contínuo, tendo como referência a perspectiva do conselho como um processo democratizante e inclusivo.

Não se pode deixar de mencionar o importante papel da sociedade civil nesse processo, pois a atuação (e não a presença) dos conselheiros é o elo fundamental para a mudança de paradigma envolta aos conselhos de unidades de conservação, substituindo o foco da participação tecnocrática para uma participação efetiva e inclusiva, em todos os níveis. A gestão participativa prevista no arcabouço legal dificilmente sairá do papel se não houver uma apropriação desse espaço por estes atores, que tende a fortalecer não só os objetivos do conselho como também as próprias políticas públicas relacionadas.

Por fim, reconhecemos que os obstáculos ainda são abundantes, os entendimentos são diversos e a resistência na partilha do poder de decisão persiste. Entretanto, há também um vasto campo de atuação ainda pouco explorado, na base do experimentalismo institucional (Santos \& Avritzer, 2005), a partir do qual se buscam outros olhares e novas práticas para a participação nestes fóruns, algumas sugeridas neste artigo.

\section{Referências}

Abers, R. N.; Keck, M. E. Representando a diversidade: 
Estado, sociedade e "relações fecundas" nos conselhos gestores. Caderno CRH, 21(52), 99-112, 2008.

Acselrad, H. Conflitos ambientais no Brasil. Rio de Janeiro: Relume Dumará, 2004.

Adriano, J. Rumo ao ecodesenvolvimento na zona costeira catarinense: estudo de caso sobre a experiência do fórum da agenda 21 local da lagoa de Ibiraquera, no período de 2001 a 2010. Florianópolis, Dissertação (Mestrado em Sociologia Política) - UFSC, 2011.

Alves, R. P.; Hanazaki, N. Áreas protegidas marinho-costeiras de Santa Catarina sob a perspectiva das populações locais. Ambiente \& Sociedade, 18(4), 97-188, 2015.

Andrade, J.; Scherer, M. E. G. Decálogo da gestão costeira para Santa Catarina: avaliando a estrutura estadual para o desenvolvimento do Programa Estadual de Gerenciamento Costeiro. Desenvolvimento e Meio Ambiente, 9, 139-154, 2014.

Avritzer, L. A qualidade da democracia e a questão da efetividade da participação: mapeando o debate. In: Pires, R.R.C. (Org). Efetividade das instituições participativas no Brasil: estratégias de avaliação. Brasília: Instituto de Pesquisa Econômica Aplicada, p. 13-28, 2011.

Boni, V.; Quaresma S. J. Aprendendo a entrevistar: como fazer entrevistas em Ciências Sociais. Em Tese, 2(3), 6880, 2005.

Costa, R. G. Gestão compartilhada: uma perspectiva para a efetiva implementação da Reserva Biológica Marinha do Arvoredo. Florianópolis, Dissertação (Mestrado em Engenharia de Produção) - UFSC, 2003.

Dagnino, E. Sociedade civil, espaços públicos e a construção democrática no Brasil: limites e possibilidades. In: Dagnino, E. (Org.). Sociedade civil e espaços públicos no Brasil. São Paulo: Paz e Terra, 9-15, 2002.

Dagnino, E. Construção democrática, neoliberalismo e participação: os dilemas da confluência perversa. Política \& Sociedade, 5, 137-161, 2004.

Delgado, N. G; Nonnal, P; Leite, S. P. Desenvolvimento territorial: articulação de políticas públicas e atores sociais. Observatório de Políticas Públicas para a Agricultura (OPPA), 2007. Disponível em <www.oppa.net.br/acervo/ publicações>. Acesso em mai. 2017.

Dias-Neto, J. Pesca no Brasil e seus aspectos institucionais - um registro para o futuro. Biodiversidade e Conservação Marinha, 1(1), 66-80, 2010.

Gil, A. C. Métodos e técnicas de pesquisa social. São Paulo: Atlas, 5. ed., 1999.

Gohn, M. G. Conselhos Gestores e Participação Sociopolítica. São Paulo: Cortez, 3. ed., 2007.

Haimovici, M.; Andriguetto Filho, J. M.; Sunye, P. S. A pesca marinha e estuarina no Brasil: estudos de caso multidisciplinares. Rio Grande: Editora da FURG, 2014.

IBAMA. Plano de Manejo da Reserva Biológica Marinha do Arvoredo, 2004. Disponível em: <www.icmbio.gov. $\mathrm{br} /$ rebioarvoredo/o-que-fazemos/manejo-e-conservacao. html>. Acesso em jan.2017.

Irving, M. A. Governança democrática e gestão participativa de áreas protegidas. In: Bensusan, N.; Prates, A. P. (Orgs.). A diversidade cabe na unidade? Áreas protegidas no Brasil. Brasília: Mil Folhas, p. 166-182, 2014.

Joventino, F. K. P.; Johnsson, R. M. F.; Lianza, S. Pesca artesanal na baía de Ilha Grande, no Rio de Janeiro: conflitos com unidades de conservação e novas possibilidades de gestão. Política \& Sociedade, 12(13), 159-182, 2013.

Lavalle, A. G. Participação: valor, utilidade, efeitos e causa. In: Pires, R. R. C. (Org). Efetividade das instituições participativas no Brasil: estratégias de avaliação. Brasília: Instituto de Pesquisa Econômica Aplicada, p. 33-42, 2011.

Loureiro, C. F. B.; Cunha, C. C. Educação ambiental e gestão participativa de unidades de conservação: elementos para se pensar a sustentabilidade democrática. Ambiente \& Sociedade, 11(2), 237-253, 2008.

Lüchmann, L. H. H. Os Conselhos Gestores de Políticas Públicas: desafios do desenho institucional. Ciências Sociais Unisinos, 38(161), 43-79, 2002.

Lüchmann, L. H. H. Os sentidos e desafios da participação. Ciências Sociais Unisinos, 42(1), 19-26, 2006.

Marconi, M. A.; Lakatos, E. M. Fundamentos de metodologia científica. São Paulo: Atlas, 5. ed., 2003. 
Martins, I. M. Conhecimento ecológico de pescadores artesanais sobre peixes de interesse comercial: contribuições para o manejo e conservação na baía de Tijucas, SC. Florianópolis, Dissertação (Mestrado em Ecologia) - UFSC, 2012.

Martins, I. M.; Medeiros, R. P.; Hanazaki, N. From fish to ecosystems: the perceptions of fisherman neighboring a southern Brazilian marine protected area. Ocean \& Coastal Management, 91, 50-57, 2014.

Medeiros, R. P. Possibilidades e obstáculos à co-gestão adaptativa de sistemas pesqueiros artesanais: estudo de caso na área da baía de Tijucas, litoral centro-norte do estado de Santa Catarina, no período de 2004 a 2008. Florianópolis, Tese (Doutorado em Sociologia Política) - UFSC, 2009.

Mendonça, F.; Talbot, V. Participação social na gestão de unidades de conservação: uma leitura sobre a contribuição do Instituto Chico Mendes. Biodiversidade Brasileira, 4(1), 211-234, 2014.

MMA - Ministério do Meio Ambiente. Gestão Participativa do SNUC. Brasília: Ministério do Meio Ambiente, Série Áreas Protegidas do Brasil, 2, 2004.

Rebouças, G. N.; Filardi, A. C. L.; Vieira, P. F. Gestão integrada e participativa da pesca artesanal: potencialidades e obstáculos no litoral do Estado de Santa Catarina. Ambiente e Sociedade, 9(2), 83-104, 2006.

Santos, B. S.; Avritzer, L. Para ampliar o cânone democrático. In: Santos, B. S (Org.). Democratizar a democracia: os caminhos da democracia participativa. Rio de Janeiro: Civilização Brasileira, 3. ed., 13-27, 2005.

Seixas, C. S.; Kalikoski, D. C. Gestão participativa da pesca no Brasil: levantamento das iniciativas e documentação dos processos. Desenvolvimento e Meio Ambiente, 20, 119-139, 2009.
Silva, M. K. Entre a norma e o factual: questões para uma análise sociológica dos processos de participação social na gestão pública. Política \& Sociedade, 5, 187-202, 2004.

Steenbock, W.; Santos, R. A.; Macedo, H. S.; Almeida, E. G.; Silva, M. C.; Medeiros, R. P.; Vizuete, E. P. Até onde posso arrastar? - Construindo acordos sobre os limites da pesca artesanal de arrasto na Baía Norte de Florianópolis frente à legislação ambiental. Biodiversidade e Conservação Marinha, 4(1), 29-45, 2015.

Strenzel, G. M. R. Programa de monitoramento ambiental da Reserva Biológica Marinha do Arvoredo, Santa Catarina, Brasil: uma proposta metodológica. Florianópolis, Dissertação (Mestrado em Geografia) - UFSC, 1997.

Tatagiba, L. Os conselhos gestores e a democratização das políticas públicas no Brasil. In: Dagnino, E. (Org.). Sociedade civil e espaços públicos no Brasil. Rio de Janeiro: Paz e Terra, p. 47-103, 2002.

Vasconcellos, M.; Diegues, A. C.; Sales, R. R. Limites e possibilidades na gestão da pesca artesanal costeira. In: Costa, A. L. (Org.). Nas redes da pesca artesanal. Brasília: IBAMA, 2-70, 2007.

Vivacqua, M. Conflitos socioambientais no litoral de Santa Catarina: O caso da Reserva Biológica Marinha do Arvoredo. Florianópolis, Dissertação (Mestrado em Sociologia Política) - UFSC, 2005.

Vivacqua, M.; Vieira, P. F. Conflitos socioambientais em unidades de conservação. Política \& Sociedade, 7, 139$162,2005$.

Zhouri, A.; Laschefski, K. Desenvolvimento e conflitos ambientais. Belo Horizonte: Editora UFMG, 2010. 